\title{
Effect of structural modifications on the drying kinetics of foods: changes in volume, surface area and product shape
}

\author{
Antonio De Michelis ${ }^{\mathrm{a}, \mathrm{c}^{*}}$, Carlos A. Márquez ${ }^{\mathrm{b}}$, Alejandra Mabellini ${ }^{\mathrm{b}, \mathrm{c}}$, Elizabeth \\ OHACO $^{\text {b }}$, AND SERgio A. Giner ${ }^{\mathrm{d}}$ \\ a INTA AER El Bolsón. Mármol 1950 (8430) El Bolsón, Río Negro, Argentina \\ ${ }^{\text {b }}$ Facultad de Ciencias y Tecnología de los Alimentos. Universidad Nacional del Comahue. 25 de Mayo y \\ Reconquista (8336) Villa Regina, Río Negro, Argentina \\ ${ }^{\text {c }}$ C.O.N.I.C.E.T. Rivadavia 1917 (1917) CABA, Argentina \\ d CIDCA, Departamento de Ingeniería Química, Facultad de Ingeniería, Universidad Nacional de La Plata - \\ Comisión de Investigaciones Científicas de la Provincia de Buenos Aires (CIC). Calle 47 y 116 (1900) La Plata, \\ Argentina \\ ${ }^{*}$ Corresponding author \\ demichelis.antonio@inta.gob.ar \\ TEL: +542944492422 \\ FAX: +542944492422
}

Received: 29 November 2012; Published online: 18 October 2013

\begin{abstract}
Macro and micro-structural changes take place during food dehydration. Macro-structural changes encompass modifications in shape, area and volume. Studies of such changes are important because dehydration kinetics (essential for calculating industrial dryers) may be highly influenced by changes in food shape and dimensions. The overall changes in volume, surface area ("shrinkage") and shape (Heywood factor, with provides a close description of food shape) were determined experimentally, and the results were correlated with simple expressions. Hence, although dehydration kinetics can be modeled with simplified overall shrinkage expressions, the possibility of selecting a suitable geometry and predicting the characteristics dimensions will provide higher accuracy. An additional unresolved problem is the lack of a general model that predicts macro-structural changes for various foods and diverse geometries. In this work, based on experimental data of sweet and sour cherries, and rose hip fruits, a simplified general model to predict changes in volume and surface area are proposed. To estimate how the changes in characteristic dimensions affect the kinetic studies, experimental drying curves for the three fruits by means of a diffusional model considered the following variants for the characteristic dimensions: (i) The radius of the fresh food, assumed constant; (ii) The radius of the partially dehydrated product; (iii) The radius predicted by the correlation for structural changes, especially volume, obtained in this work and generalized for the three fruits, and (iv) to demonstrate the need to study the macro-structural changes for all dehydrated foods, also be present the case of a restructured food.
\end{abstract}

Keywords: food drying; Structural changes; Volume area and shape changes; Kinetics; Experimental; Modelling 


\section{Introduction}

Drying is probably the oldest method used to preserve food but, nowadays, it is not only considered as such, but also as a technique to add value to primary products. Drying produces today numerous and diverse end products, easily employed to satisfy modern diets (Ramos, Brandao, \& Silva, 2003) as well as stabilizes raw materials that are processed further or are a source of extracted bioactive compounds, which will then be incorporated in other products (Devahastin \& Niamnuy, 2010). Drying decreases water activity in the food material, thus minimizing microbial growth and physical and chemical changes during storage. Current demand for high quality products in the food market requires elevated retention of nutritional and sensory attributes in dehydrated foods compared with the fresh raw materials. To this end, a complete understanding of the factors responsible for quality losses is becoming more and more important (El-Aouar et al., 2005).

Food tissues are dynamic systems whose structure and composition can vary during storage, processing, distribution and home preparation for consumption, depending on factors such as: its initial composition, acidity, internal pressure, interaction of the processing method and environmental conditions such as relative humidity, ambient pressure and temperature (BarbosaCánovas, Juliano, \& Peleg, 2004).

During dehydration, water migrates through the cell membranes and walls of foods, to then flow via a more or less porous structure towards the drying medium. Moisture content gradients developing inside the product produce microstructural stresses leading to shrinkage and deformation. Shrinkage occurs as the tissue is unable to retain its structural mesh when the watercontaining spaces are continuously emptied and refilled with air, while the external structure collapses. The phenomenon known as "case hardening" influences shrinkage mechanisms in the whole product (Panyawong \& Devahastin, 2007; Falade \& Abbo, 2007).

Studies of shrinkage are difficult to tackle from knowledge of the physical and chemical phenomena occurring during drying, but they are useful anyway since the determination of dehy- dration kinetics can be considerably influenced by changes in the characteristic dimensions of the drying food. Most published contributions propose studies of the actual facts, i.e., experiments are carried out for several controlled operating conditions and the results are regressed in terms of simple empirical models which consider the overall changes in food volume and/or surface area. In addition, some authors consider that the evaluation of particle shrinkage alone is not sufficient, since shape changes are not taken into account. In this sense, several authors began to use also the shape changes to some foods (Jinorose \& Devahastin, n.d.; Panyawong \& Devahastin, 2007; Gumeta-Chavez et al., 2011; Gaston, Abalone, Giner, \& Bruce, 2003; Chaves, Sgroppo, \& Avanza, 2003; Toma Vanacore, Chaves, \& J.R. 2006; Costa et al., 2011; Marquez \& De Michelis, 2011).

Panyawong and Devahastin (2007) have introduced a method for treating experimental data based on the Heywood shape factor. This provides a more realistic description of the shape change in a food. Therefore, the extent of deformation will be related with the magnitude of the change in the Heywood shape factor during drying. This treatment is necessary since shrinkage is neither symmetrical nor uniform in most foods, in spite of which, most researchers have assumed that shrinkage does not depend on drying operating conditions or, at most, that it depends on drying rate (Panyawong \& Devahastin, 2007; Moreira, Figueiredo, \& Sereno, 2000; Arnosti, Freire, \& Sartori, 2000; Hatamipour \& Mowla, 2002, 2003; Ratti, 1994; Raghavan \& Venkatachalapathy, 1999; Schultz et al., 2007; Calli Pacco \& Menegalli, 2004; Ochoa, Kesseler, Pirone, Marquez, \& De Michelis, 2002a, 2002b; Ochoa, Kesseler, Pirone, Marquez, \& De Michelis, 2007; Marquez, De Michelis, \& Giner, 2006; Pirone et al., 2008; Marquez \& De Michelis, 2011; Mabellini, Beatriz Vullioud, Alberto Marquez, \& De Michelis, 2010). On the other hand, deformation is considered to depend on drying rate and drying method (Panyawong \& Devahastin, 2007).

Although the modelling of dehydration kinetics with simplified overall shrinkage models is possible, a more strict and rigorous treatment would imply the consideration of shape changes based 
on determinations of characteristic dimensions of the food. Another drawback in shrinkage studies is that a general model is lacking for different type of foods and shapes. These characteristics are very important for engineering calculations in the agro food industry because if not considering the changes in volume, area and shape, processing times may be poorly estimated since if the mass diffusion coefficients do not account for the decrease volume, the characteristic dimension of food used in the simulation models will be greater than the real dimension of the food particles.

This work is based on published data on shrinkage during drying (Ochoa et al., 2002a, 2002b; Ochoa et al., 2007; Marquez et al., 2006; Pirone et al., 2008; Marquez \& De Michelis, 2011; Mabellini et al., 2010) which were measured for sweet and sour cherry and rose hip fruits. The purpose is to develop a simplified, though general model describing volume and surface area changes in the three fruits. The Heywood shape factors will be evaluated for the fruits studied in this work, so as to assist in the selection of a suitable geometry to represent the fruits. The case of a restructured fruit product experiencing shrinkage during drying will also be presented, as an example that in all cases it is necessary to evaluate the macro-structural changes (Leiva Diaz, Giannuzzi, \& Giner, 2009). On the other hand, experimental data predictions of drying kinetics will be compared according to the type of characteristic dimension used for the products: (a) constant, taken before drying; (b) a value for the partially dehydrated product, depending on the particular study of each product; (c) The characteristic dimension will be calculated by a correlation describing volume changes, to be developed in this work with the aim of being general, valid for the three fruits.

\section{Materials and Methods}

\section{$2.1 \quad$ Materials}

\section{Fruits}

Fresh fruits were selected and calibrated for this study. Fruits were maintained in cold stores at $4{ }^{\circ} \mathrm{C}$ and $92 \%$ relative humidity until re- quired. Their main characteristics are listed in Table 1 (Ochoa et al., 2002a, 2002b; Ochoa et al., 2007; Pirone et al., 2008). A mechanical pretreatment was applied to rose hip fruits in order to speed up drying times: it consisted of puncturing each fruit at three equatorial equidistant points, using a $1.1 \mathrm{~mm}$ diameter needle. Using this procedure, drying times were reduced by 57 \% (Ohaco, Mabellini, Márquez, De Michelis, \& Lozano, 2009; Mabellini, Ohaco, Márquez, De Michelis, \& Lozano, 2012).

\section{Restructured product}

Apples var. Granny Smith were purchased in a local market and stored at $10{ }^{\circ} \mathrm{C}$ for $24 \mathrm{~h}$ before use. Fruits were washed, peeled, cut in halves, cored, cut into $14 \mathrm{~mm}$ dices, and steam-blanched (400 g of sample over 4,800 $\mathrm{ml}$ of boiling water at atmospheric pressure) for $600 \mathrm{~s}$ to avoid enzymatic browning, to soften the tissues and to allow pectins to be dissolved and distributed before gelation. As the use of blanched apple puree alone led to a poor quality dehydrated pectic gel, $79 \mathrm{~g}$ of puree was added with $18 \mathrm{~g}$ of sucrose and $3 \mathrm{~g}$ of an aqueous solution of citric acid $(0.174 \%$ $\mathrm{w} / \mathrm{w})$, (moisture content of $70.6 \%$ ), before drying to enhance the pectin-sugar-acid gelation. The blanched apple dices were pureed and mixed with the ingredients in an electric blender (Braun Multiquick Advantage, MR-4050, Spain) for 2 $\min$.

\subsection{Methods}

\section{Dehydration}

\section{Fruits}

Whole fruits were dehydrated, without peduncle and with or without pretreatment. Air flowed through the fruits, in experimental, closed-cycle equipment with forced air (Fig. 1), which allowed operating conditions to be controlled and regulated.

The drying chamber, which was designed for about $0.35 \mathrm{~kg}$ of fresh fruit, contained a meshbottomed tray to hold the sample of particles. The tray was easily removed or replaced sideways for periodic weighing of the sample. Air leakage 
Table 1: General characteristics of the fruits employed in this work

\begin{tabular}{lcccc}
\hline $\begin{array}{l}\text { Fruits (Variety) } \\
\text { Sweet cherry }\end{array}$ & $\begin{array}{c}\text { Refractometric } \\
\text { soluble solids }\end{array}$ & $\begin{array}{c}\text { Water content }(\mathrm{kg} \\
\text { water/kg dry matter })\end{array}$ & $\begin{array}{c}\text { Equatorial } \\
\text { diameter }(\mathrm{m})\end{array}$ & $\begin{array}{c}\text { Axial diameter } \\
(\mathrm{m})\end{array}$ \\
\hline $\begin{array}{l}\text { (Napolitana) } \\
\text { Sour cherry } \\
\text { (Montmorency) }\end{array}$ & $16-21$ & $3.31-3.74$ & $0.0162-0.0196$ & $0.0141-0.0165$ \\
$\begin{array}{l}\text { Rose hip } \\
\text { (Rosa rubiginosa) }\end{array}$ & $19-21$ & $3.29-3.39$ & $0.0143-0.0161$ & $0.0139-0.0157$ \\
\hline
\end{tabular}

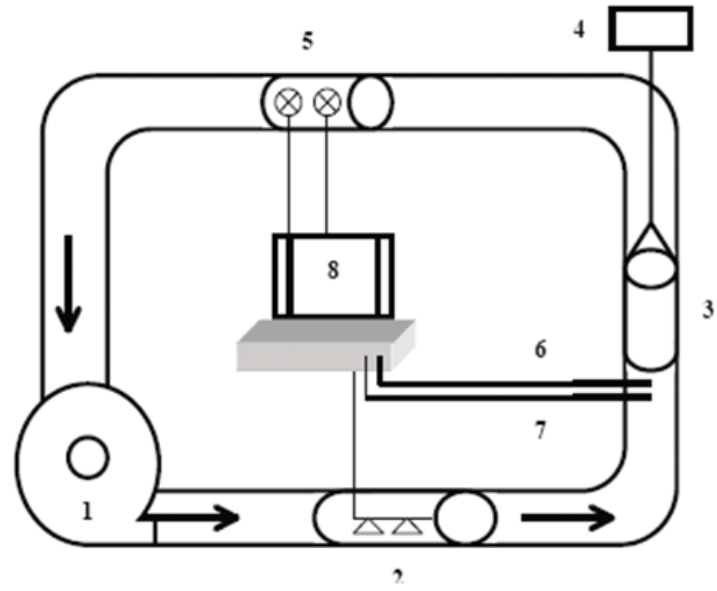

Figure 1: Scheme of the experimental equipment employed in this work 1 . Variable speed fan. 2. Relative humidity conditioner, with saturated salt solutions. 3. Removable drying chamber. 4. Balance. 5. PC-controlled electric heater, using a purpose-developed Visual Basic Program 6. Data logger for dry bulb temperature of air. 7 . Relative humidity meter. 8. Personal Computer (PC).

was prevented using rubber stripping. Air temperature was measured with thermocouples inserted in the drying chamber and connected to a digital thermometer (Digi-Sense, Cole-Parmer Instrument Company; Vernon Hills, IL, USA, \pm $0.5{ }^{\circ} \mathrm{C}$ ). Air velocity was measured with a Mini Vane CFM Thermo Anemometer (EXTECH Instruments; Waltham, MA, USA, 0.4 to 35 $\mathrm{m} / \mathrm{s}$, and accuracy $\pm 2 \%$ ). In turn, relative humidity was determined with a Hygro Palm hygrometer (Rotronic Instruments; West Sussex, UK; Range: 0 to $100 \%, \pm 1.5 \% \mathrm{RH}$, at $23 \pm 5$ $\left.{ }^{\circ} \mathrm{C}\right)$.

The set of operating conditions used was as follows:

- Air temperature: 50, 55, 60, 65, 70, 75 and $80{ }^{\circ} \mathrm{C}$

- Air velocity 1.0, 1.8 and $2.5 \mathrm{~m} / \mathrm{s}$

- Air relative humidity 5 and $50 \%$

- All operating variables were measured at the inlet of the dryer chamber

\section{Restructured product}

Food tissues and gel foods experience considerable shrinkage during hot-air drying (Ratti, 1994; Bhandari \& Howes, 1999). This is because the process evolves while the material is in its rubbery region (Roos, 1995). As water is removed in hot-air drying, the material cannot withstand its own weight and collapses; this aspect often reduces organoleptic quality in cellular foods, although not in pectic gels. During drying, the apple formulation changes from a fluid-like appearance to a soft paste texture and, finally, to a firm gel. To study the volume variation and the drying kinetic, the initial formulation was placed into acrylic trays $(0.18 \times 0.138 \times 0.013 \mathrm{~m})$, with an initial thickness of $6 \times 10^{-3} \mathrm{~m}$, and was dehydrated at $60{ }^{\circ} \mathrm{C}$ in a forced convection oven, with parallel air flow, to several moisture contents (Leiva Diaz et al., 2009). 


\section{Determination of weight differences and of dry weight}

\section{Fruits}

Except the initial moisture content, which was determined by an mechanical convection oven at $104{ }^{\circ} \mathrm{C}$ until constant weight, all other experimental points of the drying curve were determined by sample weighing (Ohaus, NJ, USA, \pm $0.001 \mathrm{~g}$ ), assuming constant dry mass of the sample during drying. Each experimental point informed is the average of three repetitions with a maximum variance of $7.2 \%$.

\section{Restructured product}

Moisture content was determined in a vacuum oven by the AOAC technique 22.018 (AOAC, 1984). All measurements were carried out in triplicate. Replicates did not differ by more than 0.3 $\%$.

\subsection{Determination of changes in volume, surface area, and of the shape factor}

\section{Fruits}

\section{Volume changes}

Pycnometric method: This consists of determining the weights of: a $100 \mathrm{~cm}^{3}$ glass bottle called pycnometer with a close-fitting ground glass stopper with a capillary tube through it, so that air bubbles may escape from the apparatus, of the bottle filled with toluene, of the bottle plus the fresh or partially dehydrated fruit sample added to it and of toluene required to fill the bottle (digital balance Ohaus, NJ-USA, \pm 0.001 g). By knowing the density of toluene at the temperature of the experiment, and after carrying out the appropriate calculations, the volume of toluene displaced by the sample can be known, which equals the sample volume. In that way the sample density was determined.

Geometric measurements: By taking the maximum transversal dimension and the major axis of fruits using a micrometer (Starrett 2MARL, Buenos Aires, $\pm 0.01 \mathrm{~mm}$ ) (Clemente,
Bon, Cárcel, Garcia-Pascual, \& Mulet, 2000; Lozano, Rotstein, \& Urbicain, 1983; Ochoa et al., 2002a; Ratti, 1991; Ratti, 1994; Suzuki, Kubota, Hasegawa, \& Hosaka, 1976), and taking the shape of prolate spheroid to calculate the volume. All reported volumes are average of values from 12 fruits of the same calibrated size in each condition.

\section{Superficial area changes}

Changes in the surface area, per unit volume, of particles were evaluated from the geometric measurements, carried out as mentioned in the previous section and then calculating the approximate surface area/unit volume by a paraboloid of revolution. The surface area values are approximated since its measurement was not possible (Ratti, 1994; Suzuki et al., 1976). Presented data were averaged from 12 fruits under the same conditions of drying.

\section{Determination of the Heywood shape factor}

This shape factor can be mathematically defined as (Panyawong \& Devahastin, 2007; Pirone et al., 2008):

$$
K=\frac{V_{p}}{d_{a}^{3}}
$$

where $V_{p}$ is the particle volume and da is the equivalent diameter of the projected area of the particle and is obtained from:

$$
d_{a}=\sqrt{4 A_{P} / \pi}
$$

where $A_{p}$ is the projected area of particles in the most stable rest position. The projected area of particles was obtained by assigning the area of an equivalent circle with the same greater diameter (equatorial) as that of the fruit.

\section{Restructured product}

\section{Volume and density changes}

Ochoa et al. (2002a) found that volume and area changes are independent from drying conditions and only related to the product moisture content. For each level of moisture content, the sample thickness was measured with the depth probe of 
a Vernier caliper $( \pm 0.1 \mathrm{~mm})$ at six positions in the tray; the results were averaged. The product surface area was measured with a precision ruler (readability $0.5 \mathrm{~mm}$ ). Density was calculated from the product volume and the product mass (OHAUS Adventurer digital balance \pm 0.01 g; OHAUS Corp., USA). Determinations were conducted in triplicate.

\section{Results and discussion}

\section{$3.1 \quad$ Fruits}

\section{Volume and superficial area changes}

In order to better describe the method used to evaluate volume and surface area changes in whole fruits, the case of rose hip fruits will be presented here (from Ochoa et al. (2002a)), both without (published experimental values, Ochoa et al. (2002a)) and with pretreatment (experimental values obtained in this paper).

In Fig. 2, the relative particle volumes $\left(V / V_{o}\right)$ of partially dehydrated samples (both pretreated and not pretreated) were plotted as a function of their relative moisture contents $\left(X / X_{o}\right)$, for several temperatures. Information was presented based on results of statistical analysis (ANOVA, $\alpha=0.01$; Software: InfoStat/ Professional vs. 1.1) indicated no statistical differences between pretreated and not pretreated samples $(\mathrm{p}=0.473)$ and between samples that were dehydrated at various temperatures $(\mathrm{p}=0.754)$. Volumes determined by pycnometry differed between -10.4 and $+9.1 \%$ with respect to the geometrical versions and the maximum standard deviation was $7.2 \%$.

Volume shrinkage has been studied, among others, by Kilpatrick, Lowe, and Van Arsdel (1975), Lozano, Rotstein, and Urbicain (1980), Lozano et al. (1983), Ochoa et al. (2002a), Pezzutti (1994), Ratti (1991), Ratti (1994) and Suzuki et al. (1976) who, from specific experimental data for different foods, have proposed correlations to evaluate the changes. The model by Suzuki et al. (1976) described the changes by means of a straight line. Lozano et al. (1983) modified that model for situations where two straight lines may be necessary: one for high and another for low $(X<0.15)$ water contents. Lozano et al. (1983) and Pezzutti (1994) proposed a nonlinear equation to represent the behavior of experimental data:

$$
\begin{aligned}
& \frac{V}{V_{o}}=0.161+0.816 \frac{X}{X_{o}}+\ldots \\
& \ldots 0.022 e^{0.018 /(X+0.025)}+\ldots \\
& \ldots\left(0.209-\frac{0.966}{X_{o}+0.796}\right)\left(1-\frac{X}{X_{o}}\right)
\end{aligned}
$$

Pezzutti (1994) modified the Eq. (3) for garlic, which is valid at very low moisture contents:

$$
\begin{aligned}
& \frac{V}{V_{o}}=0.161+0.816 \frac{X}{X_{o}}+\ldots \\
& \ldots 0.022 e^{0.018 /(X+0.025))}+\ldots \\
& \ldots\left(0.209-\frac{0.729}{X_{o}+0.018}\right)\left(1-\frac{X}{X_{o}}\right)
\end{aligned}
$$

Ratti (1991), Ratti (1994) found, in foods such as carrots and pears, that the $V / V_{o}$ vs $X / X_{o}$ function is linear over the entire water content range. However, in other products she observed another behavior that may be represented by two linear segments. The same author has suggested that a change in the dehydration mechanism takes place at critical relative water content $\left(X / X_{o}\right)_{c}$, which reflects a change in the ratio of internal to external resistances to mass transfer. For that reason, she proposed that volume changes caused by shrinkage can be predicted by:

$$
\begin{array}{ll}
\frac{V}{V_{o}}=a_{1}+b_{1} \frac{X}{X_{o}} & {\left[\frac{X}{X_{o}}\right]_{c} \leq \frac{X}{X_{o}} \leq 1} \\
\frac{V}{V_{o}}=a_{2}+b_{2} \frac{X}{X_{o}} & 0 \leq \frac{X}{X_{o}} \leq\left[\frac{X}{X_{o}}\right]_{c}
\end{array}
$$

In those cases where only one straight line can be used to predict the entire range, Ratti (1991) considered that the critical relative moisture content is:

$$
\left[\frac{X}{X_{o}}\right]_{c}=0
$$

Values of $a_{1}, b_{1}, a_{2}, b_{2}$ and $\left[\frac{X}{X_{o}}\right]_{c}$ were deter- 
mined by fitting the straight lines to the experimental data, using the least squares method.

For sour cherries Ochoa et al. (2002a) started from a model resembling Eq. (5) and (6) and found the following coefficients:

$$
\frac{V}{V_{o}}=0.2021+08189 \frac{X}{X_{o}}
$$

and $\left[\frac{X}{X_{o}}\right]_{c}=0$

From experimental data obtained in this work, another regression was carried out with the models indicated in Eqs. (3) and (8) and all new parameters were obtained as shown in Eqs. (9) and (10), respectively.

$$
\begin{aligned}
& \frac{V}{V_{o}}=0.161+0.816 \frac{X}{X_{o}}+\ldots \\
& \ldots 0.022 e^{0.018 /(X+0.025))}+\ldots \\
& \ldots\left(0.209-\frac{0.466}{X_{o}+0.796}\right)\left(1-\frac{X}{X_{o}}\right)
\end{aligned}
$$

$\mathrm{R}^{2}=0.955$

As can be seen in Eq. (9) only the parameter 0.466 was changed wen compared with Eq. (3). This is reasonable since a change in the slope of the line represents the experimental values, as shown in Fig. 2.

$$
\frac{V}{V_{o}}=0.2521+0.7373 \frac{X}{X_{o}}
$$

$\mathrm{R}^{2}=0.954$

Fig. 2 also shows predictions (in lines) of the Eqs. (3), (4), (8), (9) and (10).

Also, Table 2 lists percentage errors of the comparison between the experimental data of volume shrinkage of the fruits studied and the predictions from Eqs. (3), (4), (8), (9) and (10). Results from Table 2 show that Eqs. (3) and (4) and the regression based on Eq. (8) do not provide a close description of volume changes in rose hip fruits. Likewise, as models by Lozano et al. (1983) and Ochoa et al. (2002a), modified in this work Eq. (9) and (10) respectively, had lower errors, they were selected to be fitted to the shrinkage volume data of rose hip fruits. These results are also shown in Table 2.

From Table 2, errors of model-predicted values by Eqs. (9) and (10) with respect to experimental values of volume shrinkage are considerably lower and similar. Moreover, Fig. 3 depicts the experimental relative surface area $\left(A / A_{0}\right.$ being $A$ the surface area/unit volume of partially dehydrated particles and $A_{0}$ their initial value) of rose hip fruits with and without pretreatment, as a function of $X / X_{0}$, for various drying temperatures. The results present a maximum standard deviation of $9.2 \%$.

Changes in surface area are observed to clearly correlate with the relative moisture content, but neither the initial moisture content, drying temperature nor pretreatment had any statistical significance.

The trend observed for the data of surface area is in agreement with findings from previous authors working on different products Ochoa et al. (2002a), Pezzutti (1994) and Ratti (1991), Ratti (1994). They have observed that the changes occurring in surface area with the relative moisture content also depend on the type of food and initial geometry and proposed a third degree polynomial to describe the experimental behavior.

In Fig. 3, the polynomial correlation developed in this work, whose parameters were obtained from nonlinear regression of experimental data, is plotted in solid line to describe 150 experimental points with $\mathrm{R}^{2}=0.93$ (software SYSTAT v. 7.0 was used):

$$
\begin{aligned}
& \frac{A}{A_{o}}=-0.3774\left(\frac{X}{X_{o}}\right)^{3}+0.8923\left(\frac{X}{X_{o}}\right)^{2}+\ldots \\
& \ldots-1.056\left(\frac{X}{X_{o}}\right)+1.5477
\end{aligned}
$$

The Eq. (11) is similar to that found by Ochoa et al. (2002a). Percentage errors of Eq. (11) are between -8.28 and $7.14 \%$.

In sweet and sour cherries, changes of volume and surface area due to macro-structural modifications were not dependent on drying conditions either, being only a function of the water content of the partially dehydrated samples. By applying the same methodology to rose hip fruits, the models which best represented the changes were included in Table 3 , together with those for rose hip. 
Effect of shrinkage on the drying kinetics of foods $\mid 195$

Table 2: Percentage errors between the experimental values of volume change for whole rosehip fruits, with and without pretreatment, and models from Eqs. (3), (4), (8), (9) and (10): Maximum, minimum, average and average of absolute values errors and Variance

\begin{tabular}{|c|c|c|c|c|c|}
\hline \multirow[b]{2}{*}{ Model } & \multicolumn{4}{|c|}{ Error \% } & \multirow[b]{2}{*}{ Variance } \\
\hline & $\begin{array}{l}\text { Maxi- } \\
\text { mum }\end{array}$ & $\begin{array}{l}\text { Mini- } \\
\text { mum }\end{array}$ & Average & $\begin{array}{c}\text { Average of } \\
\text { absolute errors }\end{array}$ & \\
\hline Lozano et al. (1983), Eq. (3) & 5.5 & -140.3 & -54.1 & 54.3 & 9.76 \\
\hline Pezzutti (1994), Eq. (4) & 1.8 & -229.9 & -86.7 & 86.8 & 14.40 \\
\hline Ochoa et al. (2002a), Eq. (8) & 14.9 & -34.0 & -3.9 & 8.0 & 5.43 \\
\hline $\begin{array}{l}\text { Lozano et al. (1983) modified in this work } \\
\text { eq. (9) }\left(\mathrm{R}^{2}=0.955\right) \\
\text { Ochoa et al. (2002a). modified in this work }\end{array}$ & 22.6 & -21.4 & 1.6 & 8.1 & 5.02 \\
\hline eq. $(10)\left(R^{2}=0.954\right)$ & 23.1 & -21.4 & 1.3 & 8.2 & 4.94 \\
\hline
\end{tabular}

Table 3: Models developed to evaluate changes in the relative volume and surface areas of cherry, sour cherry and rose hip fruits as a function of the relative moisture content (corresponding errors included).

\begin{tabular}{|c|c|c|}
\hline Fruit & Volume changes & Surface area changes \\
\hline Cherry & $\begin{array}{r}\frac{V}{V o}=0.2407+0.7534+\frac{X}{X o} \\
\text { Error } \% \\
\text { Minimum: }-24.88 \\
\text { Maximum: } 19.63 \\
\text { Average: }-4.01 \\
\text { Variance \%: } 5.56\end{array}$ & $\begin{array}{r}\frac{A}{A o}=-0.8594\left(\frac{X}{X o}\right)^{3}+1.8395\left(\frac{X}{X o}\right)^{2}-1.557\left(\frac{X}{X o}\right)+1.5729 \\
\text { Error \% } \\
\text { Minimum: }-3.53 \\
\text { Maximum: } 6.92 \\
\text { Average: } 2.33 \\
\text { Variance \%: } 4.32\end{array}$ \\
\hline Sour Cherry & $\begin{array}{r}\frac{V}{V o}=0.2021+0.8189+\frac{X}{X o} \\
\text { Error } \% \\
\text { Minimum: }-13.62 \\
\text { Maximum: } 12.46 \\
\text { Average: } 0.17 \\
\text { Variance \%: } 6.5\end{array}$ & $\begin{array}{r}\frac{A}{A o}=-0.3774\left(\frac{X}{X o}\right)^{3}+0.8923\left(\frac{X}{X o}\right)^{2}-1.0656\left(\frac{X}{X o}\right)+1.5477 \\
\text { Error } \% \\
\text { Minimum: }-6.86 \\
\text { Maximum: } 6.92 \\
\text { Average: } 0.13 \\
\text { Variance \%: } 2.73\end{array}$ \\
\hline Rose hip fruits & $\begin{array}{r}\frac{V}{V o}=0.2521+0.7373+\frac{X}{X o} \\
\text { Error } \% \\
\text { Minimum: }-21.4 \\
\text { Maximum: } 23.1 \\
\text { Average: } 1.3 \\
\text { Variance \%: } 4.94\end{array}$ & $\begin{array}{r}\frac{A}{A o}=-0.3774\left(\frac{X}{X o}\right)^{3}+0.8923\left(\frac{X}{X o}\right)^{2}-1.0656\left(\frac{X}{X o}\right)+1.5477 \\
\text { Error } \% \\
\text { Minimum: }-8.3 \\
\text { Maximum: } 7.1 \\
\text { Average: }-0.7 \\
\text { Variance } \%: 3.62\end{array}$ \\
\hline
\end{tabular}

Being $V$ the fruit volume, $V_{o}$ its initial value, $X$ the fruit moisture content and $X_{o}$ its initial value.

In turn, $A$ is the surface area of the fruit and $A_{o}$ the initial surface area. 
$196 \mid$ De Michelis et al.

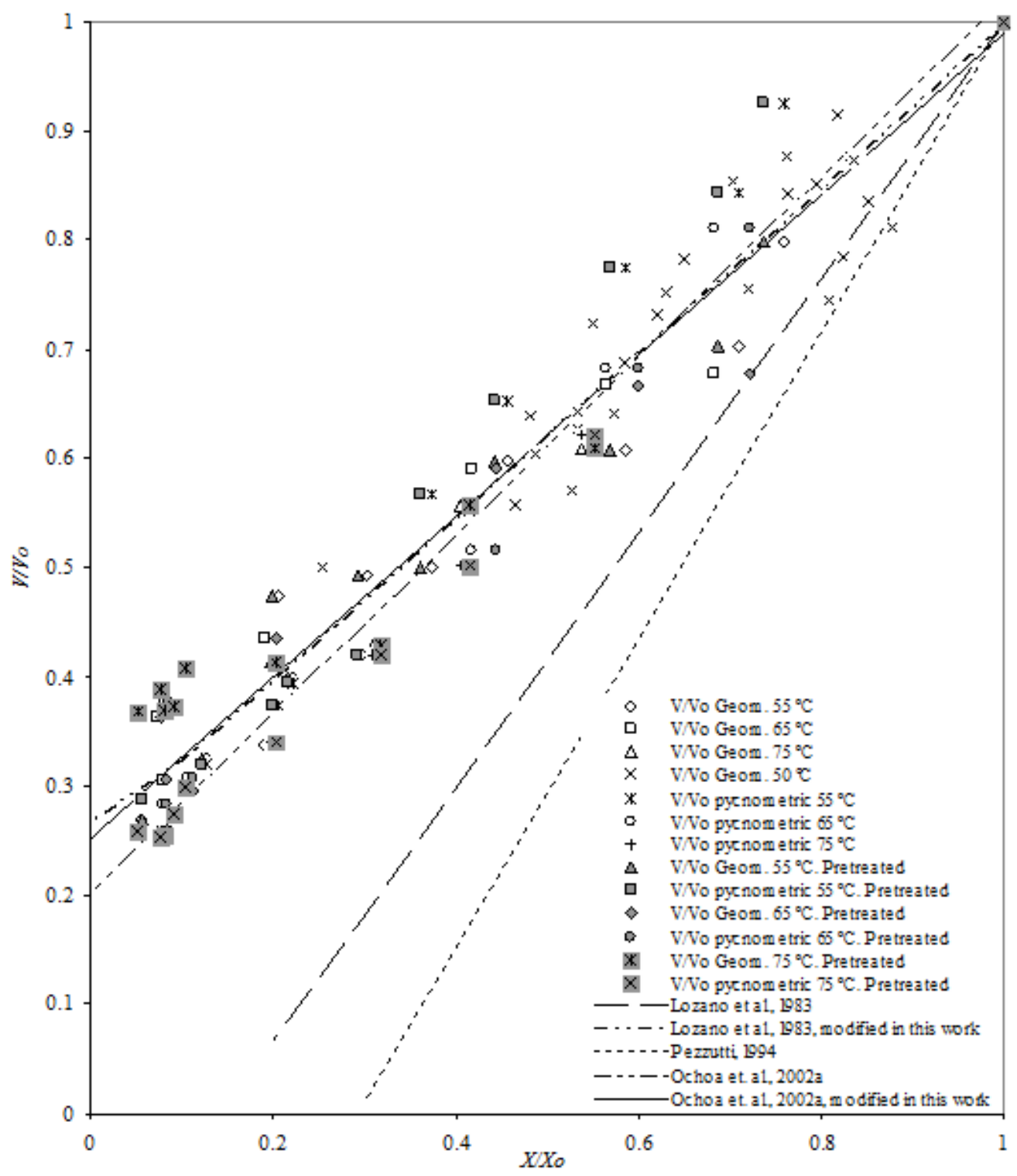

Figure 2: Relative volume as a function of the relative water content for pretreated and not pretreated rose hip fruits, dehydrated at different drying air temperatures. 
Effect of shrinkage on the drying kinetics of foods $\mid 197$

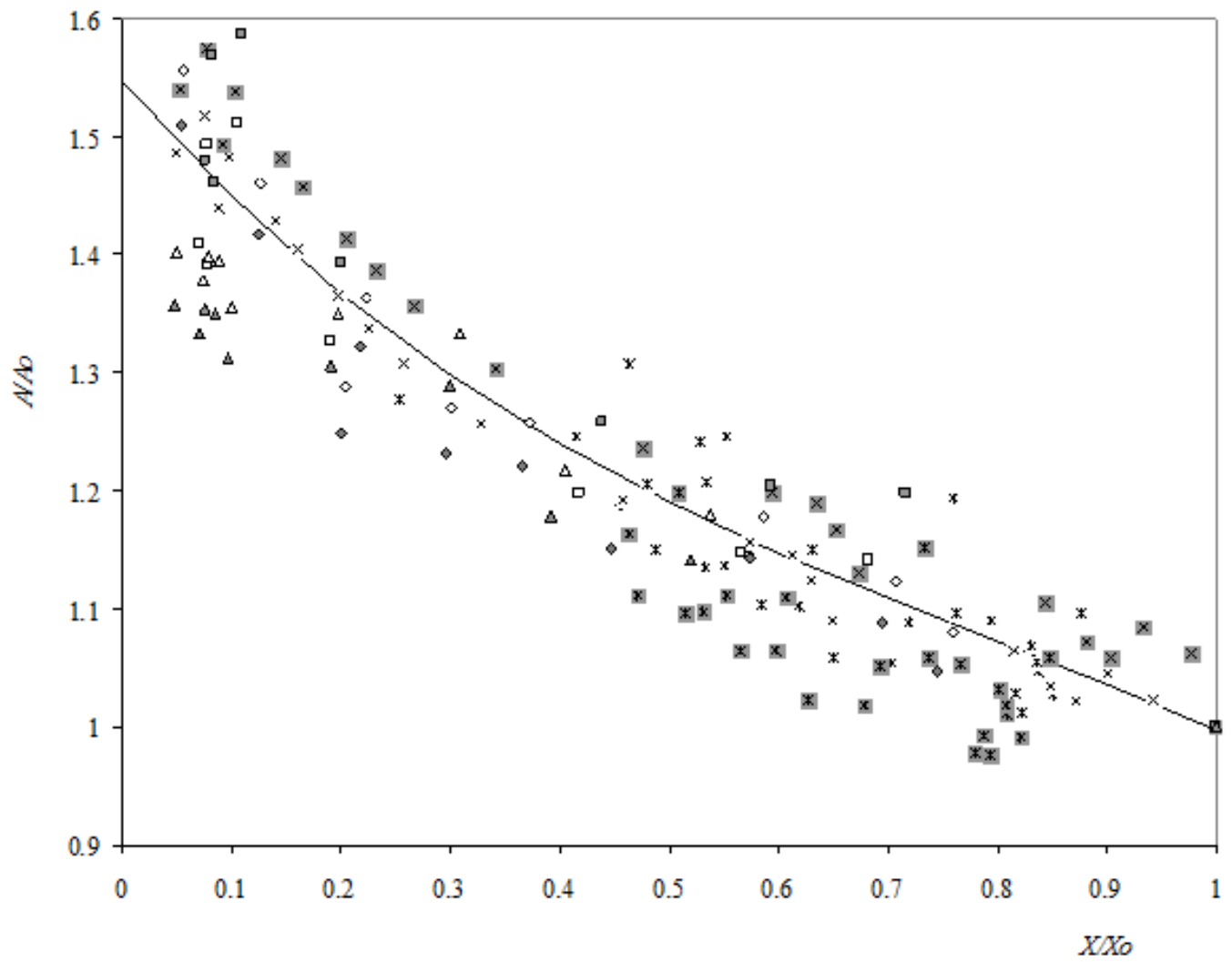
× $50^{\circ} \mathrm{C}$
a. Pretreated $50^{\circ} \mathrm{C}$
- $55^{\circ} \mathrm{C}$
- Pretreated $55^{\circ} \mathrm{C}$
$\times 60^{\circ} \mathrm{C}$
$\times$ Pretreated $60^{\circ} \mathrm{C}$
- $65^{\circ} \mathrm{C}$
- Pretreated $65^{\circ} \mathrm{C}$
$\triangle 75^{\circ} \mathrm{C}$
$\triangle \quad$ Pretreated $75^{\circ} \mathrm{C} \quad$ Eqn (8)

Figure 3: Relative surface area $\left(A / A_{o}\right)$ of particles as a function of the relative water content $\left(X / X_{o}\right)$ for pretreated and not pretreated whole rose hip fruits at various drying air temperatures. The solid line represents model-predicted values by Eq. (11) 


\section{Development of a general model to predict changes in volume and surface area of the fruits studied in the present work}

As observed in Table 3, models obtained for volume and surface area changes in sweet and sour cherries and rose hip fruits are similar; for this reason a generalization was attempted. By representing $V / V_{0}$ for the three fruits and fitting a new straight line to them, the results were

$$
\frac{V}{V_{o}}=0.2437+0.7373 \frac{X}{X_{o}}
$$

whose percentage errors were: $23.1 \%$ to -23.4 $\%$; average, $0.9 \%$ and Standard deviation of the estimate of 2.3 .

The complete experimental data of $V / V_{0}$ for the three fruits, together with the line predicted with Eq. (12), as a function of $X / X_{o}$, were plotted in Fig. 4.

In turn, Fig. 5 depicts the distribution of percentage errors of predictions by Eq. (12) with reference to experimental data of $V / V_{0}$, as a function of the experimental $X / X_{0}$. As observed in Fig. 5, higher percentage errors were caused by very low relative moisture contents, below 0.15 , whose moisture content corresponded to a water activity of 0.6 in rose hip fruits (Vullioud, Marquez, \& De Michelis, 2004) and 0.62 in sour and sweet cherry fruits (Vullioud, Marquez, \& De Michelis, 2006), these water activities being almost endpoints of the dehydration process.

Likewise, by representing the experimental points of $A / A_{0}$ vs $X / X_{0}$ for the three fruits, and fitting a cubic polynomial expression to them, Eq. (13) was obtained:

$$
\begin{aligned}
& \frac{A}{A_{o}}=-0.2771\left(\frac{X}{X_{o}}\right)^{3}+0.6720\left(\frac{X}{X_{o}}\right)^{2}+\ldots \\
& \ldots-0.9052\left(\frac{X}{X_{o}}\right)+1.5079
\end{aligned}
$$

Percentage errors of Eq. (13) were 6.5 to $-9 \%$; average $0.1 \%$ and Standard deviation of the estimate of 2.3. Results as well as Eq. (13) values of
$A / A_{0}$ were plotted as a function of $X / X_{0}$ in Fig. 6 . It can be observed that the errors of general correlations, Eqs. (12) and (13), are similar to those of fruit-specific correlations already shown in Table 3.

\section{Determination of Heywood shape factors in sweet and sour cherry and rose hip fruits}

Experimental shape factors, the maximum variance obtained on 12 repetitions was $4.3 \%$, determined for sweet and sour cherry and rose hip fruits were plotted as a function of $X / X_{0}$ in Fig. 7 , together with the average shape factor for fresh fruits (solid line), and of a sphere (dashed line). For the three fruits, Heywood shape factors are observed to evolve towards the value corresponding to a sphere as drying proceeds. This behavior would allow the spherical shape to be selected in order to determine the characteristic dimensions necessary for modelling drying kinetics.

\section{$3.2 \quad$ Restructured product}

\section{Volumetric Shrinkage}

Shrinkage of pectic gels during drying was onedimensional; the product retained its plane sheet shape unaltered during drying. This behavior agreed with that observed for other gels by Kechaou, Roques, and Lambert (1987). For calculation the volumetric shrinkage was deduced:

$$
V=V_{o}-a V_{w e v}
$$

where $V_{o}$ is the initial volume, and $a$ is a parameter varying between 0 and 1 . Mayor and Sereno (2004) stated that materials undergoing water removal tend to reach mechanical equilibrium when shrinkage equals the volume of removed water. By assuming this behavior, $a=1$. $V_{w e v}$ is the volume of water evaporated, and is assuming constant dry matter, $m_{d}$, the mass of water evaporated, $m_{w e v}$, can be calculated by:

$$
m_{\text {wev }}=m_{d}-\left(X_{o}-X\right)
$$

Therefore, the expression of volume as a function of moisture content becomes

$$
V=V_{o}-\left(\frac{m_{d}-\left(X_{o}-X\right)}{\rho_{w}}\right)
$$


Effect of shrinkage on the drying kinetics of foods $\mid 199$

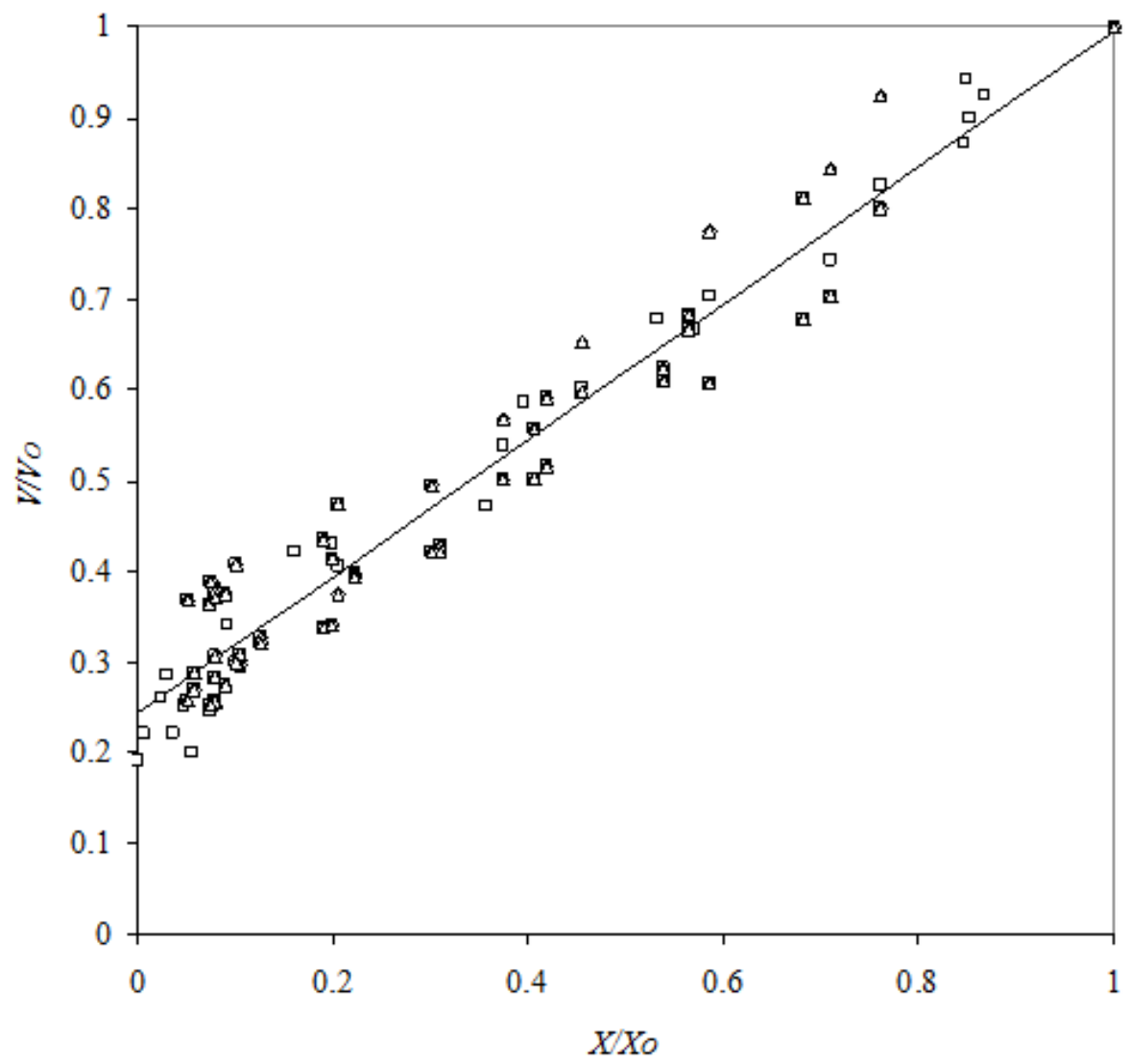

- Sweet Cherry fruits \& Sour Cherry fruits $\Delta$ Rose Hip fruits — Estimated

Figure 4: Relative volume of the three fruits as a function of the relative water content. The predicted line by Eq. (12) is also included.

Replacing $m_{d}$ by $\rho_{d}, V_{d}$, and $V_{o}$ by $V_{d}+$ $\left(\rho_{d} V_{d} X_{o} / \rho w\right)$ (the volume of the dry solid plus the initial water volume in the product), dividing both members by $V_{o}$ and rearranging, the final expression is obtained:

$$
\frac{V}{V_{o}}=\left[1-\frac{X_{o}}{\rho_{w}\left(\frac{1}{\rho_{d}}+\frac{X_{o}}{\rho_{w}}\right)}\right]+\left[\frac{1}{\rho_{w}\left(\frac{1}{\rho_{d}}+\frac{X_{o}}{\rho_{w}}\right)}\right] X
$$

The value of $\rho_{d}$, the dry matter density, was determined by pycnometry to be $1,382 \mathrm{~kg} / \mathrm{m}^{3}$. The theoretical intercept was 0.245 , representing the fraction of the initial volume that would remain in the totally dehydrated product. The results of this model (Eq. (17)) were plotted together with the experimental values in Fig. 8. Agreement was excellent, so the mechanism proposed in this study provides a correct description of shrinkage. As can be seen in Fig. 8, $V / V_{o}$ decreases to 68 $\%$, while the surface area is virtually unchanged. 


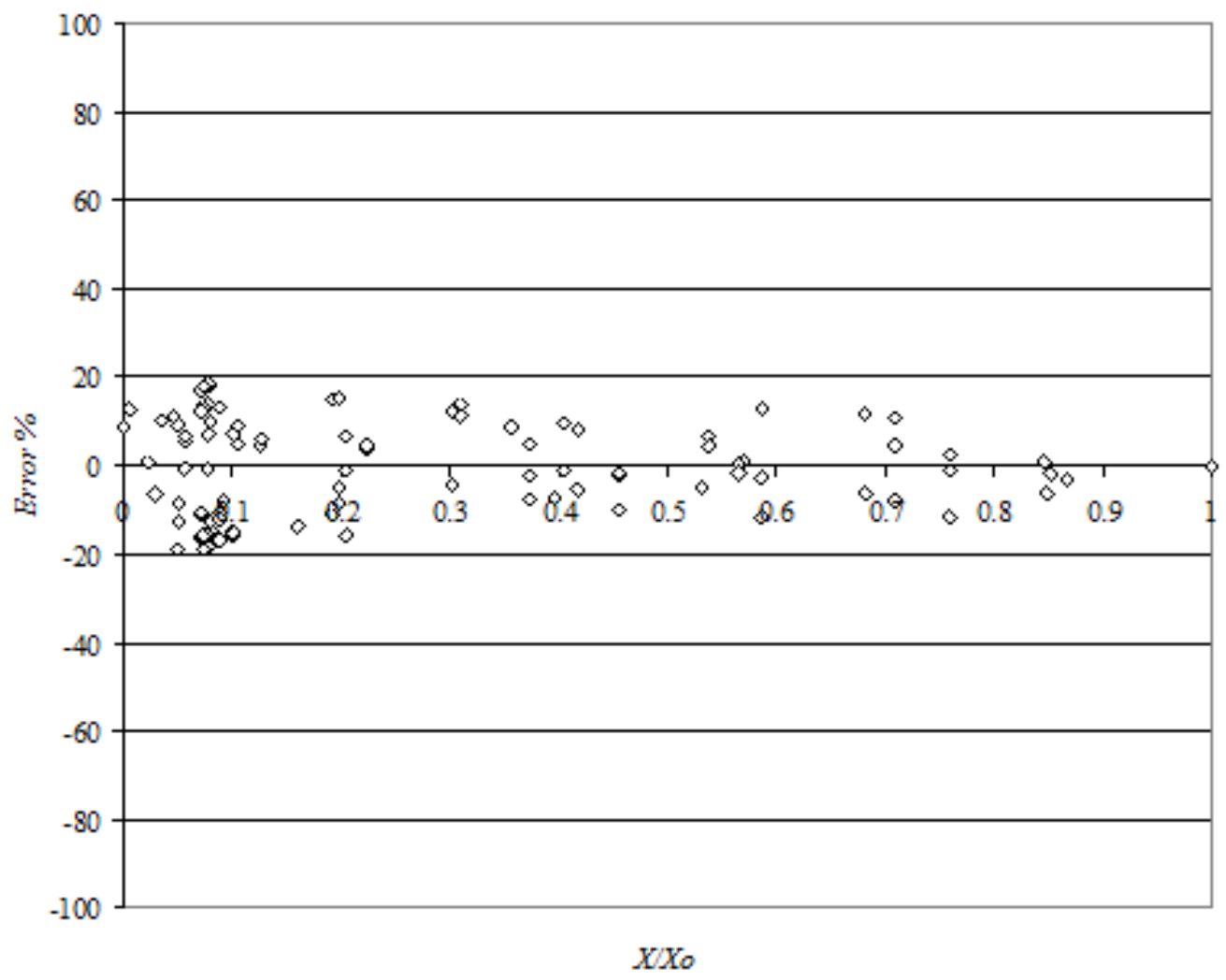

Figure 5: Percentage errors of model-predicted values of $V / V_{o}$ by Eq. (12) as a function of the experimental $X / X_{o}$ for the three fruits.

\section{Density}

The product density was calculated with the expression of Eq. (18) derived from Eq. (17):

$$
\rho=\frac{\rho_{d}(1+X)}{1+\frac{\rho_{d}}{\rho_{w}} X}
$$

This density of Eq. (18) was compared with averages of experimental data, and a satisfactory agreement can be observed in Fig. 9. Density increases as moisture decreases, particularly at lower moisture contents. The density of the material changes from $1,084 \mathrm{~kg} / \mathrm{m}^{3}$ in the initial formulation to $\rho_{d}=1,382 \mathrm{~kg} / \mathrm{m}^{3}$ for the totally dehydrated product (maximum shrinkage). As the dry solid is denser than liquid water, this behav- ior is observed in the presence of collapse: the higher the solids concentration, the higher the density. The average relative error of predictions was $1.36 \%$.

\subsection{Effect of macro-structural changes on drying kinetics of fruits}

Experimental data of drying kinetics of sweet and sour cherry and rose hip fruits were studied by considering: (a) the characteristic dimension of the fresh fruit, considered constant during drying; (b) a characteristic dimension calculated by the shrinkage model of individual fruits listed in Table 3; and (c) a variable characteristic dimen- 
Effect of shrinkage on the drying kinetics of foods $\mid 201$

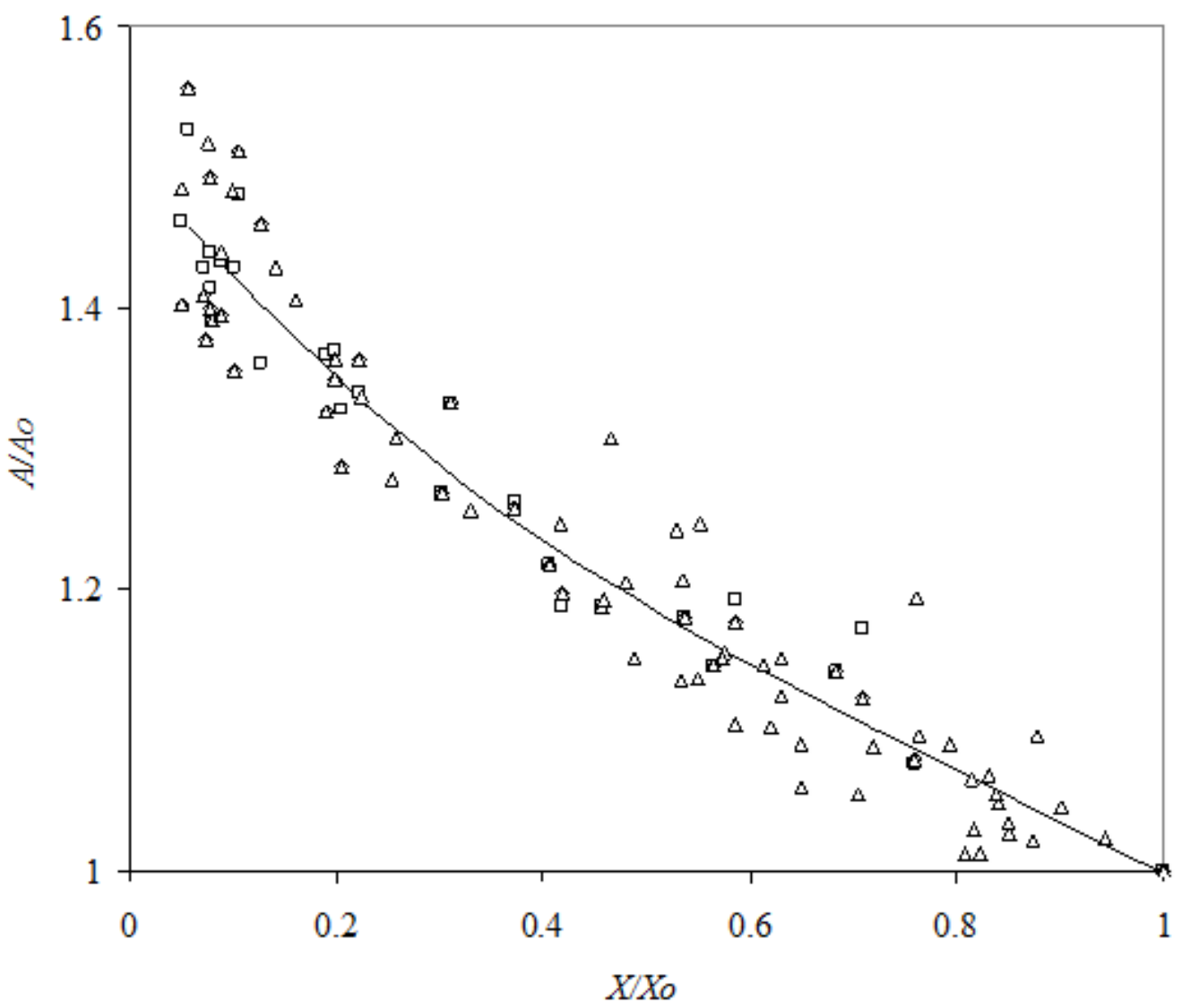

- Sweet Cherry fruits $\triangle$ Sour cherry fruits $\triangle$ Rose Hip fruits - Estimated

Figure 6: Experimental and model-predicted (Eq. (13)) values of the relative surface area of the three fruits as a function of relative moisture content. 
$202 \mid$ De Michelis et al.

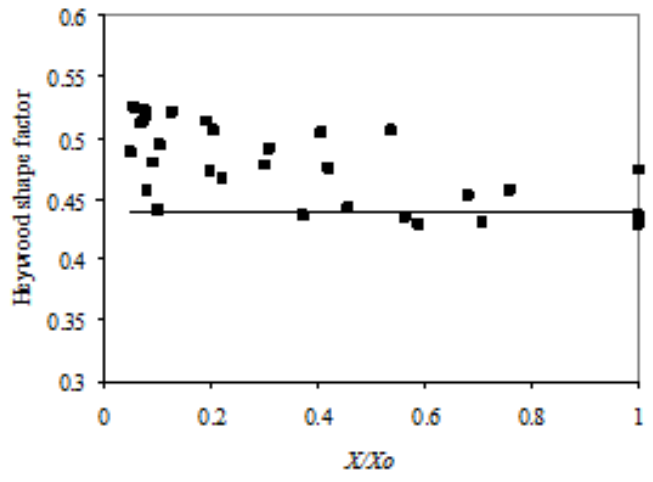

- Heywood shape factor for partially de hydrated sweet

cherries
A vera ge Heywood shape factor for fre sh sweet cheries

A

- - - Hevwood shaoe factor for sohere oarticle

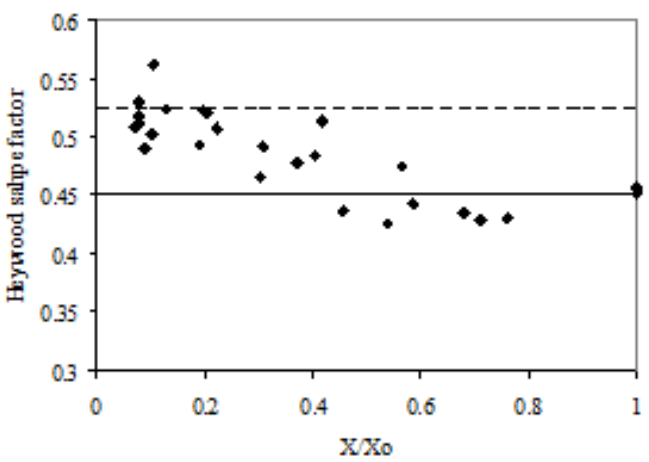

- Heywood shape factor for partially dehydrated sour cherries

- Average Heywood shape factor for fresh sour cherries

B Heywood shape factor for sphere particle

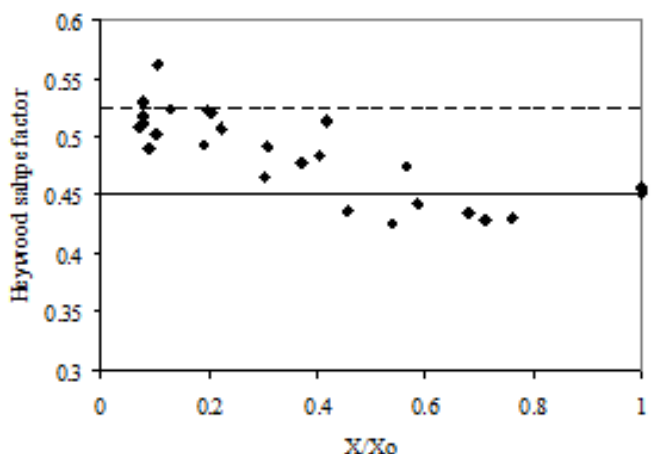

- Heywood shape factor for partially dehydrated sour cherries

- Average Heywood shape factor for fresh sour cherries

C

Heywood shape factor for sphere particle

Figure 7: Heywood shape factor for sweet cherry, sour cherry and rose hip fruits as a function of relative moisture content. The solid line represents the average shape factor for the fresh fruit, while, in dashed line, the shape factor for a sphere is illustrated. 


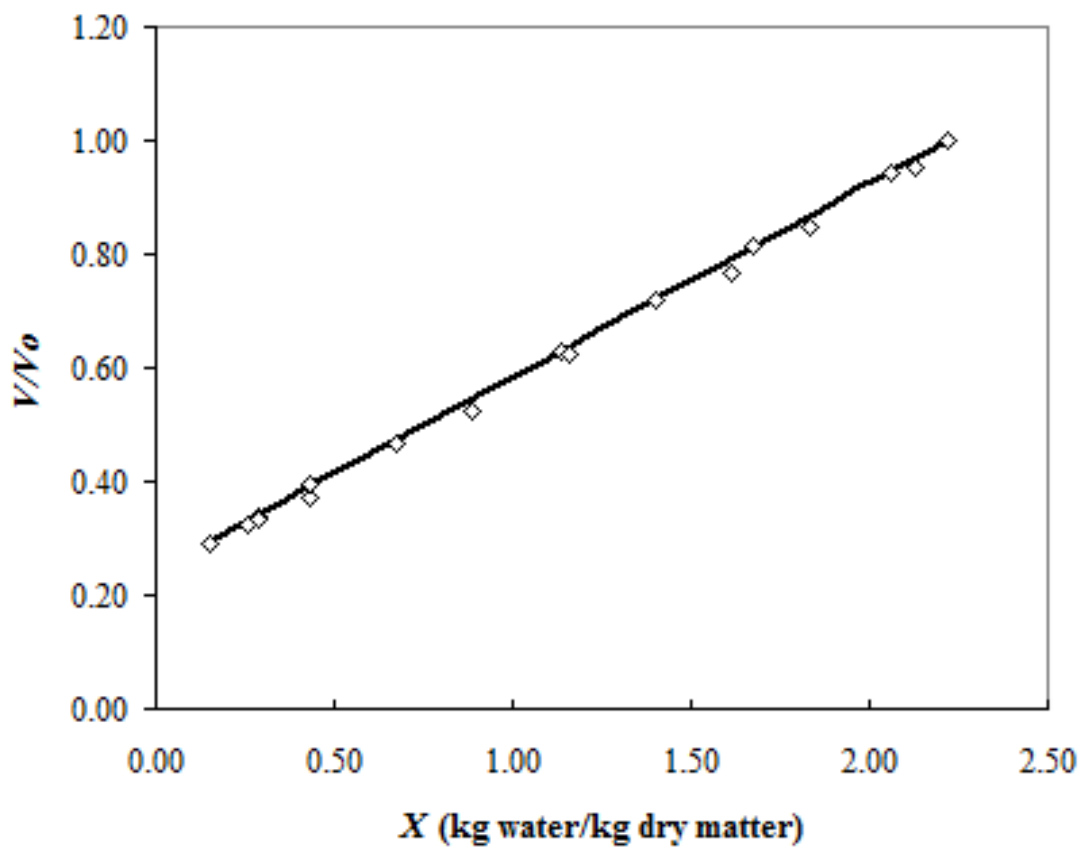

$\diamond$ Data - Model

Figure 8: Normalized volume as a function of moisture content. Experimental data and line predictions by the theoretical shrinkage model (Eq. (17)).

sion, estimated with the general correlation Eq. (11), which is valid for the three fruits.

In previous work, a diffusive drying kinetic equation developed by Becker (1959) was employed to accurately predict drying curves of rose hip fruits Marquez et al. (2006), considering variable particle radius. This equation is:

$$
X^{*}=\frac{X-X e}{X_{o}-X e}=1-\frac{2}{\sqrt{\pi}} a_{v} \sqrt{D t}+0.331 a_{v}^{2} D T
$$

where $X^{*}$ is the dimensionless moisture content; $X_{e}$ is the equilibrium moisture content; $a_{v}$ is the surface area per unit volume of the particle, which can be evaluated using its radius (if a sphere) or with the equations listed above to calculate the changes in volume and surface area for non-spherical shapes. In turn, $D$ is the effective diffusion coefficient and $t$, time. As Heywood shape factors would allow selection of spherical geometry, rose hip fruits were considered spheres of the same volume as the particle Marquez et al. (2006), whose radius is variable during drying. To improve the accuracy of calculations, the following algorithm was devised. An example will be given for spherical geometry, between the initial time $t_{0}$ and the following, $t_{0}+\Delta t$. Using the specific surface area calculated at initial time, $\mathrm{t}_{0}\left(\mathrm{a}_{v t 0}\right)$ with the initial moisture content of the fruit, the new moisture content $X$ at time $t_{0}+\Delta t$ is calculated using Eq. (19). As during the time interval, $\Delta \mathrm{t}$, the characteristic dimension has varied, a new volume, new radius and therefore new specific surface area is calculated at $t_{0}+\Delta t,\left(a_{v t_{0} \Delta t}\right)$. An average of the specific surface area is calculated $a_{v}=\left(a_{v t 0}+a_{v t 0 \Delta t}\right) / 2$ as a representative value of the fruit dimension during $\Delta t$. This is utilized again in Eq. (19) to finally recalculate 


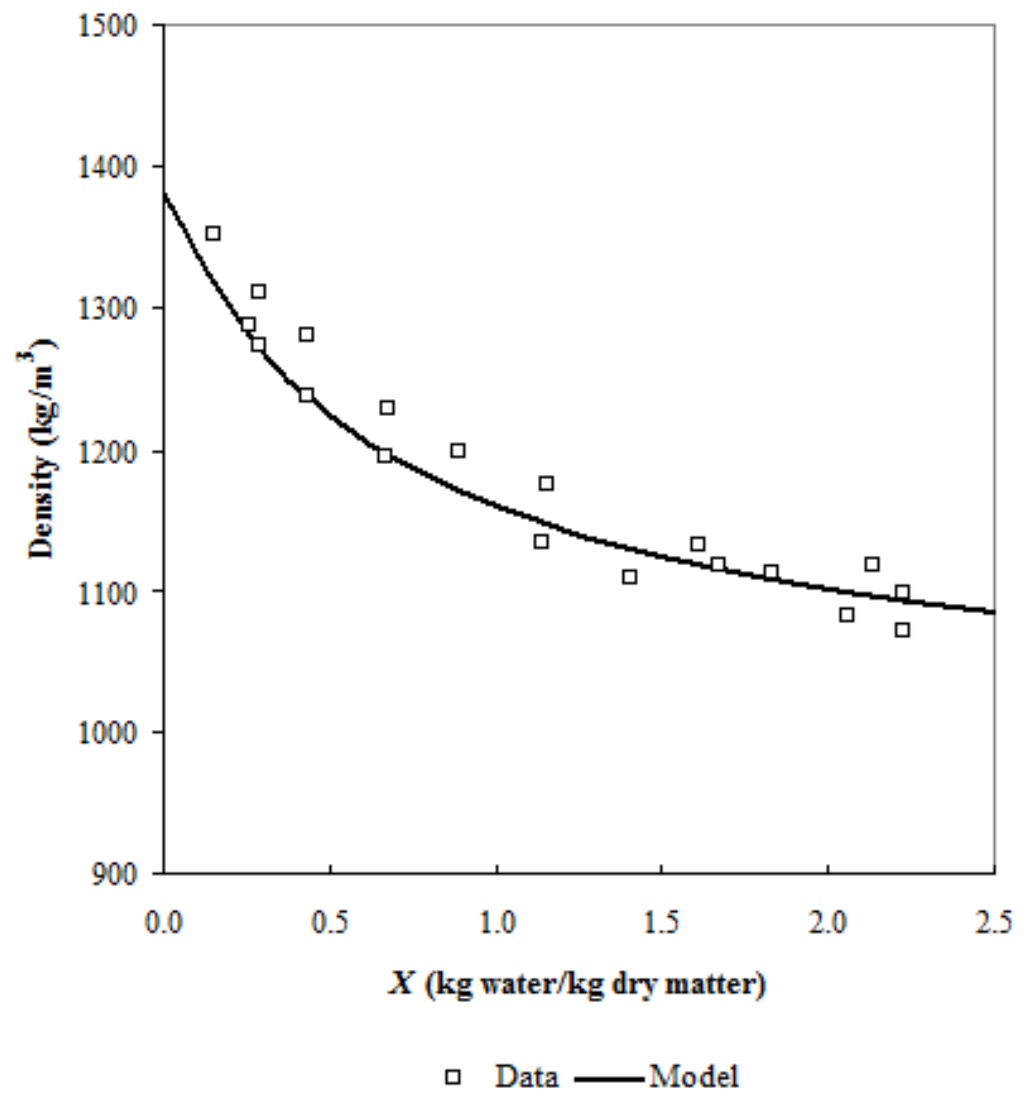

Figure 9: Product density as a function of moisture content. Experimental densities and model-predicted (Eq. (18)) values.

the moisture content at time $\left(\mathrm{t}_{0}+\Delta \mathrm{t}\right)$. For non-spherical particles, the procedure is similar with the exception that the surface area and the volume have to be calculated separately with the general correlations. As food particles, studied in this work, can be considered spherical, it is possible to obtain the characteristic dimension of the partially dry product from the equation of volume change (Eq. (11)). If the particle can not be considered spherical the characteristic dimension, $\mathrm{a}_{v}$, should be calculated from the relationship between Eqs. (12) and (13) respectively.

With regard to the equilibrium moisture content, $X e$, the sorption isotherm curves published by Vullioud et al. (2006) were utilized. On these grounds, predictions by the model of Becker were compared for three calculation situations: (a) as was calculated by Marquez et al. (2006) by considering constant radius of the fresh fruit during drying, (b) that of the partially dehydrated individually fruits calculated with the models of Table 3, and (c) that of the partially dehydrated fruit calculated with Eq. (11), valid for the three fruits.

In Fig. 10, experimental drying curves of rose hip fruits are plotted together with predictions by Eq. (19) carried out by the three calculation methods for the three calculation modes mentioned above. For variable radius, the same diffusion coefficient was employed, while for initial and constant radius, the best possible

IJFS | October 2013 | Volume 2 |pages 188-211 
Effect of shrinkage on the drying kinetics of foods $\mid 205$

Table 4: Maximum and minimum percentage errors in the prediction of the Becker model (Eq. (14)) by three calculation methods, applied to each of the three fruits

\begin{tabular}{|c|c|c|c|c|c|c|}
\hline \multirow[t]{2}{*}{ Radius } & \multicolumn{6}{|c|}{ Error \% } \\
\hline & minimum & maximum & minimum & maximum & minimum & maximum \\
\hline $\begin{array}{l}\text { - Initial, constant. The same diffusion coefficient } \\
\text { as that used in variable radius } R^{2}=0.82\end{array}$ & 0 & 180.0 & 0 & 99.6 & 0 & 97.7 \\
\hline $\begin{array}{l}\text { - Initial constant. Different diffusion } \\
\text { coefficient } \mathrm{R}^{2}=0.96\end{array}$ & -18.9 & 67.8 & -28.4 & 44.7 & -26.5 & 36.7 \\
\hline $\begin{array}{l}\text { - Variable, fruit-specific correlation (Table } 3 \text { ). } \\
\mathrm{R}^{2}>0.99\end{array}$ & -2.3 & 13.9 & -6.8 & 10.3 & -11.3 & 8.1 \\
\hline $\begin{array}{l}\text { - Variable, general correlation (Eq. (11)). } \\
\mathrm{R}^{2}>0.99\end{array}$ & -3.4 & 13.3 & -7.2 & 11.0 & -9.4 & 7.8 \\
\hline
\end{tabular}

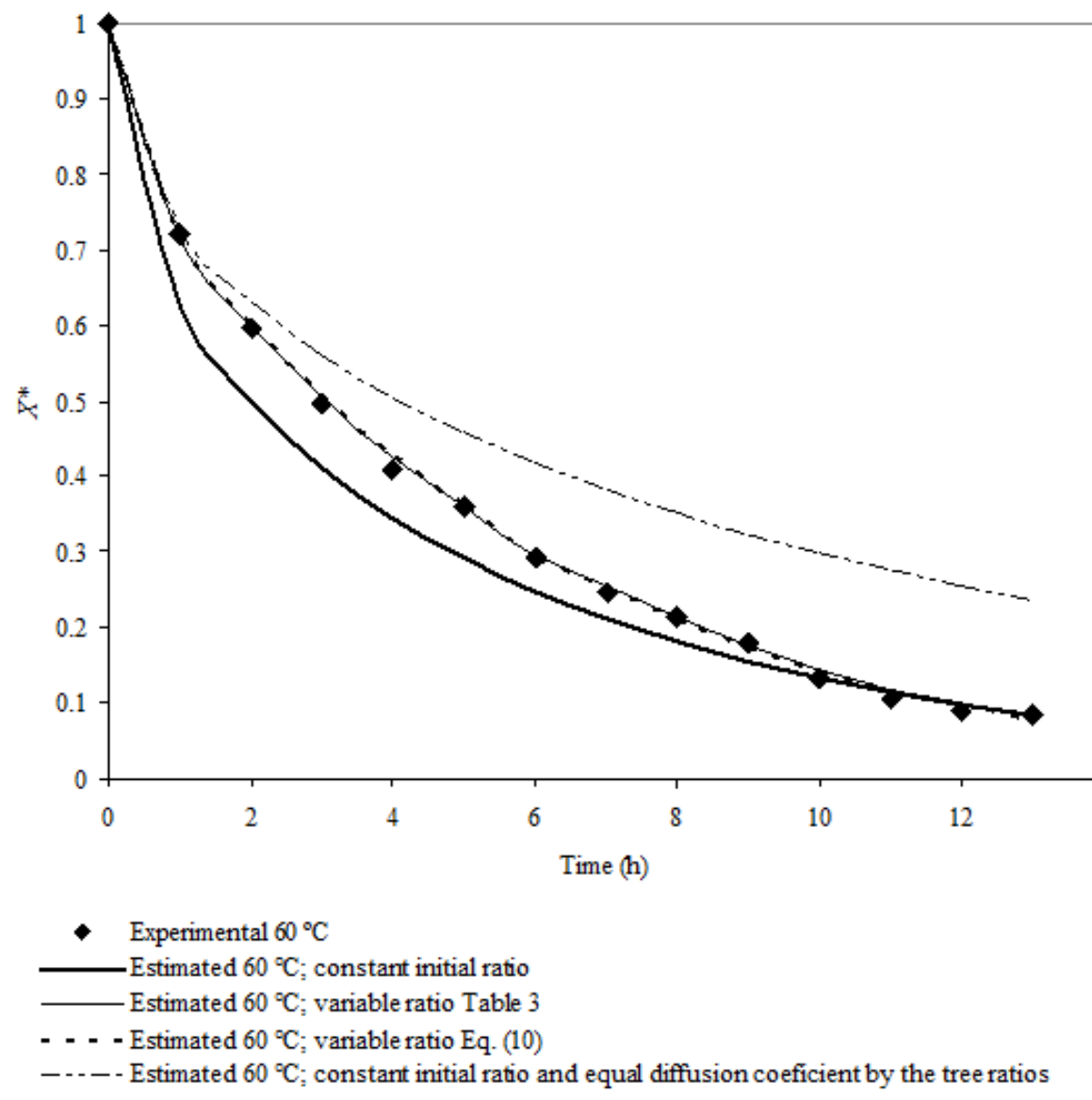

Figure 10: Experimental drying curve for rose hip fruits and model-predicted values (Eq. (19)) by three calculation modes described. Air conditions: temperature, $60{ }^{\circ} \mathrm{C}$; relative humidity, $50 \%$; velocity, 2.5 $\mathrm{m} / \mathrm{s}$. 


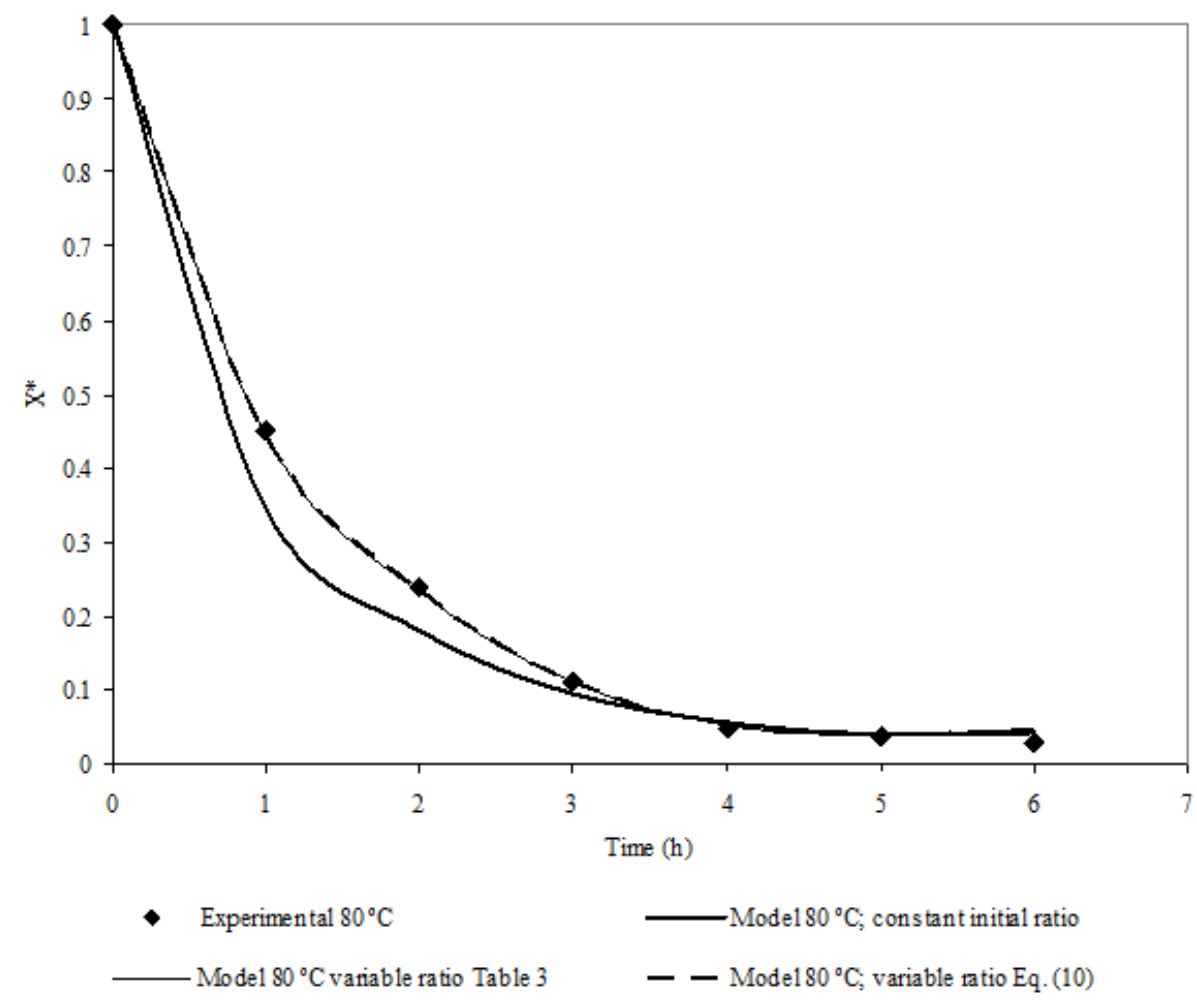

Figure 11: Experimental drying curve for sweet cherry and model-predicted values (Eq (19)) by the calculation modes described. Air conditions: temperature, $80{ }^{\circ} \mathrm{C}$; relative humidity, $5 \%$; velocity 1.0 $\mathrm{m} / \mathrm{s}$.

approximation (different diffusion coefficient) was included. Table 4 lists the percentage errors in each calculation mode and fruit.

As observed in Fig. 10 and Table 4, errors are high for fresh fruit constant radius while, on the contrary, they are fairly low when the drying curve is calculated with variable radius, calculated by the equations of Table 3 or by Eq. (11). Similar results were plotted in Figs. 11 and 12 for sweet and sour cherries, respectively, whose errors are presented in Table 4. The equilibrium moisture content $X e$ for sweet and sour cherry was calculated according to Vullioud et al. (2004). The behavior is similar to that observed in Fig. 10 for rose hip fruits. Considering the case of using the same diffusion coefficient in the three fruits, percentage errors are observed to differ particularly in rose hip fruits (Fig. 10 and Table 4).

\section{Conclusions}

On the basis of experimental data on macrostructural changes, particularly in volume and surface area of sweet and sour cherry and rose hip fruits, generalized predictive correlations were proposed whose errors were comparable to those of fruit-specific correlations.

A linear decrease was observed for fruit volume, only dependent on fruit moisture content. This behavior was also found for other authors who worked on different foods. The corresponding expression for surface area changes, on the other 


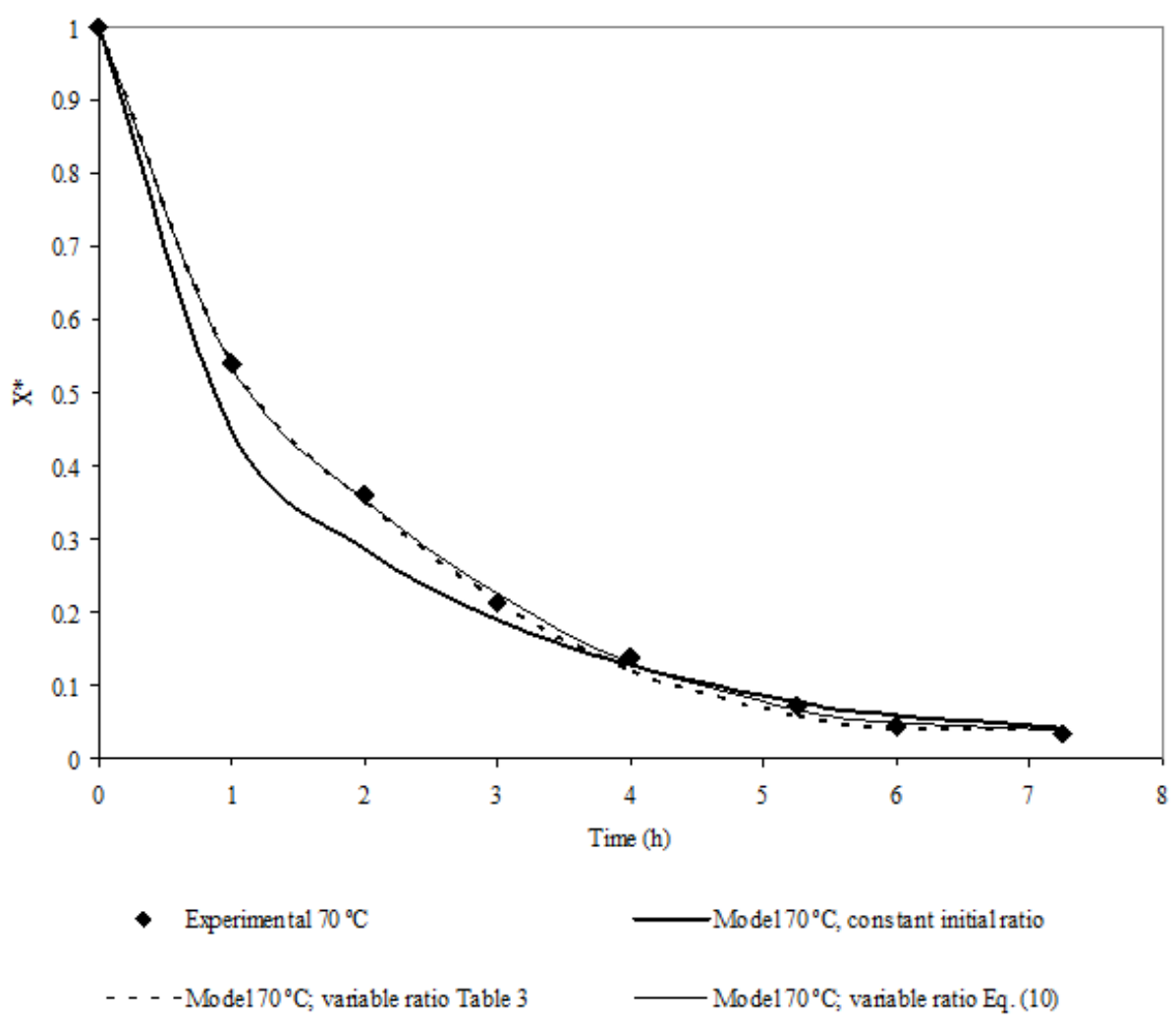

Figure 12: Experimental drying curve for sour cherries and predictions by Eq. (19) for the three calculation modes indicated. Drying air conditions, temperature, $70{ }^{\circ} \mathrm{C}$, relative humidity: $5 \%$, velocity $1.8 \mathrm{~m} / \mathrm{s}$.

hand, was a third degree polynomial that only depends on moisture content, and it is in agreement with previous literature. The corresponding generalized correlation was as similarly accurate as the fruit-specific version.

The pectic gel (laminate) was shaped in sheetlike form to reduce the drying time. Product volume decreased linearly for decreasing moisture contents, and this behavior was described with excellent agreement by a theoretical model, assuming that volume reduction equals the volume of the water evaporated. This model does not include fitting parameters, depending only on dry solids density, water density and product initial moisture content. Product volume was reduced by $68 \%$ over the process, and surface area practically did not change. Product density increases with the decrease of moisture content, and this non-linear behavior was accurately predicted with a theoretical expression based on the shrinkage model.

The behavior of whole fruits and the apple restructured product studied, even if they are examples, indicates that it is necessary to study the macro-structural changes of all products undergoing dehydration, because the changes may be very important.

The Heywood shape factors were determined for sweet and sour cherry and rose hip fruits in samples taken at different times during drying, to observe that they varied towards the value for spherical geometry. Therefore, spherical shape was selected to mathematically model the drying curves, especially because the final shape of 
fruits was similar to that of the fresh versions. In order to evaluate the influence of macrostructural changes on the prediction of drying kinetics, experimental data of moisture content as a function of time for the three fruits were compared with the corresponding predictions by a simplified diffusive model which includes a particle characteristic magnitude, the specific surface area, using the following calculation modes; (i) fresh fruit radius, considered constant; (ii) variable radius calculated by fruit-specific correlations for particle volume as a function of moisture content; and (iii) variable radius calculated from generalized correlations for particle volume developed in this work. If considering in cases (ii) and (iii) the same diffusion coefficient and the best possible value of them in case (i), the minimum and maximum percentages errors of the difference between experimental and diffusive model-predicted values of moisture content as a function of time were: case (i) between -28.4 and $67.8 \%$; case (ii) between -11.3 and $13.9 \%$ and case (iii) between -9.4 and $13.3 \%$. If the same diffusion coefficient were used in the three calculation modes, percentage errors for case (i) would vary between 0 and $196 \%$.

On the above grounds, errors in the prediction of the drying curve can be considerably high in cases where macro-structural changes are not considered so it is recommended that this subject be studied in specific conditions for each product. On the other hand, the proposed general correlation for particle volume as a function of moisture content encompassing the three fruits provides similarly accurate predictions compared with the fruit-specific correlations, when used inside the drying kinetic models.

Hence, efforts should be made in order to generalize correlations evaluating macro-structural changes as much as possible, for instance, beginning with a given type of raw materials (e.g., fruits) during drying.

\section{Acknowledgements}

The authors wish to thank Facultad de Ciencia y Tecnología de los Alimentos, Universidad Nacional del Comahue (PROIN I06-004) and CONICET (PIP 11220090100267) for financial sup- port. To CORFO - CHUBUT and INTA AER El Bolsón for providing the raw material.

\section{References}

AOAC. (1984). Official methods of analysis (14st ed.). Washington, DC, USA: Association of Official Analytical Chemists.

Arnosti, S, Freire, J., \& Sartori, D. (2000). Analysis of shrinkage phenomenon in brachiaria brizantha seeds. Drying Technology, 18(6), 1339-1348. doi:10 . 1080 / 07373930008917780

Barbosa-Cánovas, G., Juliano, P., \& Peleg, M. (2004). Engineering Properties of Foods, in Food Engineering, [Ed. Gustavo V. Barbosa-Cánovas], in Encyclopedia of Life Support Systems (EOLSS), Developed under the Auspices of the UNESCO, Eolss Publishers, Oxford ,UK, http://www.eolss. net: 1 - 32 .

Becker, H. (1959). A study of diffusion in solids of arbitrary shape, with application to the drying of the wheat kernel. Journal of Applied Polymer Science, 1(2), 212-226.

Bhandari, B., \& Howes, T. (1999). Implication of glass transition for the drying and stability of dried foods. Journal of Food Engineering, 40(1-2), 71-79. doi:10.1016 / S02608774(99)00039-4

Calli Pacco, H., \& Menegalli, F. (2004). Drying of sliced figs of "gigante de valinhos" variety (Fícus carica l). Drying 2004 - Proceedings of the $14^{\text {th }}$ International Drying Symposium (IDS 2004). São Paulo, Brazil, 22-25 August, vol. C, pp. 1851-1858.

Chaves, M., Sgroppo, S., \& Avanza, J. (2003). Cinética de secado de berenjenas (Solanum melongena L.). Comunicaciones Cientficas y Tecnológicas 2003: 1-4. Resumen: E-060. Universidad Nacional del Nordeste - Argentina.

Clemente, G., Bon, J., Cárcel, J., GarciaPascual, P., \& Mulet, A. (2000). Meat shrinkage during drying. 6 pp. Paper presented at VIII International Congress on Engineering and Food, Mexico, 9-13 April.

Costa, C., Antonucci, F., Pallottino, F., Aguzzi, J., Sun, D.-W., \& Menesatti, P. (2011). 
Effect of shrinkage on the drying kinetics of foods $\mid 209$

Shape analysis of agricultural products: a review of recent research advances and potential application to computer vision. Food and Bioprocess Technology, 4(5), 673-692. doi:10.1007/s11947-011-0556-0

Devahastin, S., \& Niamnuy, C. (2010). Modelling quality changes of fruits and vegetables during drying: a review. International Journal of Food Science and Technology, 45(9), 1755-1767. doi:10.1111/j.1365-2621. 2010.02352.x

El-Aouar, A., Moreira Azoubel, P., Kurozawa, L., Simões, M., Colato Antonio, G., \& Xidieh Murr, F. (2005). Study of Shrinkage Phenomenon During Convective Drying of Papaya (Carica papaya L.). $\left(2^{\text {nd }}\right.$ Mercosur Congress on Chemical Engineering, 2005. Río de Janeiro Brasil). $4^{\text {th }}$ Mercosur Congress on Process Systems Engineering. Pag 1-10.

Falade, K. O., \& Abbo, E. S. (2007). Airdrying and rehydration characteristics of date palm (phoenix dactylifera l.) fruits. Journal of Food Engineering, 79(2), 724730. doi:10.1016/j.jfoodeng.2006.01.081

Gaston, A., Abalone, R., Giner, S., \& Bruce, D. (2003). Geometry effect on water diffusivity estimation in prointa-isla verde and broom wheat cultivars. Latin American Applied Research, 33(3), 327-331. ENPROMER 2001 Conference, SANTA FE, ARGENTINA, SEP 16-20, 2001.

Gumeta-Chavez, C., Jorge Chanona-Perez, J., Alberto Mendoza-Perez, J., Terres-Rojas, E., Garibay-Febles, V., \& Gutierrez-Lopez, G. F. (2011). Shrinkage and deformation of agave atrovirens karw tissue during convective drying: influence of structural arrangements. Drying Technology, 29(6), 612-623. doi:10.1080/07373937.2010.514380

Hatamipour, M., \& Mowla, D. (2003). Correlations for shrinkage, density and diffusivity for drying of maize and green peas in a luidized bed with energy carrier. Journal of Food Engineering, 59(2-3), 221-227. doi:10.1016/S0260-8774(02)00461-2

Hatamipour, M., \& Mowla, D. (2002). Shrinkage of carrots during drying in an inert medium fluidized bed. Journal of Food Engineer- ing, 55(3), 247-252. doi:10.1016/ S02608774(02)00082-1

Jinorose, M., \& Devahastin, S. (n.d.). Describing deformation during drying using indicators calculated from external and microstructural changes of a food product, In The proceedings of the 5th asia-pacific drying conference (Chap. 21, pp. 158-165). doi:10 . 1142 / 9789812771957_0021. eprint: http:/ / www.worldscientific.com/doi/pdf/ 10.1142/9789812771957_0021

Kechaou, N., Roques, M., \& Lambert, J. (1987). Diffusion in shrinking media: The case of drying of gels. in physical properties of foods-2, part. 1: diffusion, paper 4 (pp. 55-60). london: elsevier applied science.

Kilpatrick, P., Lowe, E., \& Van Arsdel, W. (1975). Tunnel dehydration for fruit and vegetables. Advances in Food Research, 50, 313-372.

Leiva Diaz, E., Giannuzzi, L., \& Giner, S. A. (2009). Apple pectic gel produced by dehydration. Food and Bioprocess Technology, 2(2), 194-207. doi:10. 1007 / s11947- 007 0035- 9

Lozano, J., Rotstein, E, \& Urbicain, M. (1983). Shrinkage, porosity and bulk-density of foodstuffs at changing moisture contents. Journal of Food Science, 48(5), 1497-\&. doi:10.1111/j.1365-2621.1983.tb03524.x

Lozano, J., Rotstein, E, \& Urbicain, M. (1980). Total porosity and open-pore porosity in the drying of fruits. Journal of Food Science, 45(5), 1403-1407. doi:10.1111/j . 1365-2621.1980.tb06564.x

Mabellini, A., Ohaco, E., Márquez, C., De Michelis, A., \& Lozano, J. (2012). Effects of pretreatments in convective drying of rosehip (Rosa eglanteria). International Journal of Food Studies, 1(1), 42-51.

Mabellini, A., Beatriz Vullioud, M., Alberto Marquez, C., \& De Michelis, A. (2010). Kinetic drying experimental data and mathematical model for sweet cherries (Prunus Avium). Journal of Food Process Engineering, 33(6), 1115-1128. doi:10.1111/j.17454530.2008.00329.x

Marquez, C. A., \& De Michelis, A. (2011). Comparison of drying kinetics for small fruits with and without particle shrinkage consid- 
erations. Food and Bioprocess Technology, 4 (7), 1212-1218. doi:10.1007/s11947-0090218-7

Marquez, C. A., De Michelis, A., \& Giner, S. A. (2006). Drying kinetics of rose hip fruits (rosa eglanteria 1.) Journal of Food Engineering, 77(3), 566-574. 16th International Congress of Chemical and Process Engineering (CHISA), Prague, CZECH REPUBLIC, AUG 22-26, 2004. doi:10.1016/ j.jfoodeng.2005.06.071

Mayor, L, \& Sereno, A. (2004). Modelling shrinkage during convective drying of food materials: a review. Journal of Food Engineering, 61(3), 373-386. doi:10.1016/S02608774(03)00144-4

Moreira, R, Figueiredo, A, \& Sereno, A. (2000). Shrinkage of apple disks during drying by warm air convection and freeze drying. Drying Technology, 18(1-2), 279-294. doi:10.1080/07373930008917704

Ochoa, M. R., Kesseler, A. G., Pirone, B. N., Marquez, C. A., \& De Michelis, A. (2007). Analysis of shrinkage phenomenon of whole sweet cherry fruits (Prunus avium) during convective dehydration with very simple models. Journal of Food Engineering, 79(2), 657-661. doi:10.1016/j.jfoodeng . 2006.02 .025

Ochoa, M., Kesseler, A., Pirone, B., Marquez, C., \& De Michelis, A. (2002b). Shrinkage during convective drying of whole rose hip (rosa rubiginosa l.) fruits. LebensmittelWissenschaft Und-Technologie-Food Science and Technology, 35(5), 400-406. doi:10.1006/fstl.2001.0861

Ochoa, M., Kesseler, A., Pirone, B., Marquez, C., \& De Michelis, A. (2002a). Volume and area shrinkage of whole sour cherry fruits (Prunus cerasus) during dehydration. Drying Technology, 20(1), 147-156. doi:10 . 1081/DRT-120001371

Ohaco, E., Mabellini, A., Márquez, C., De Michelis, A., \& Lozano, J. (2009). Tiempos de secado durante la deshidratación convectiva de rosa mosqueta pretratada química y mecánicamente. Actas III Congreso Internacional de Ciencia y Tecnología de Alimentos. Córdoba - Argentina. 15 al 17 de Abril de 2009. Libro 3: Avances en Inge- niería y Tecnología. Pp:180-186 ISBN: 978987-24620-9-3.

Panyawong, S., \& Devahastin, S. (2007). Determination of deformation of a food product undergoing different drying methods and conditions via evolution of a shape factor. Journal of Food Engineering, 78(1), 151161. doi:10.1016/j.jfoodeng.2005.09.012

Pezzutti, A. (1994). Deshidratación de ajo y cebolla.Tesis Doctoral. Universidad Nacional del Sur, Bahía Blanca, Argentina.

Pirone, B., Vullioud, M., Ochoa, M., Kesseler, A., Márquez, C., \& De Michelis, A. (2008). Cambios de volumen, área superficial y factor de forma de heywood durante la deshidratación de cerezas (Prunus avium). Ciencia e Tecnologia de Alimentos - Campinas, 28(2), 317-321.

Raghavan, G., \& Venkatachalapathy, K. (1999). Shrinkage of strawberries during microwave drying. Drying Technology, 17(10), 2309-2321. doi:10 . 1080/ 07373939908917685

Ramos, I., Brandao, T., \& Silva, C. (2003). Structural changes during air drying of fruits and vegetables. Food Science and Technology International, 9(3), 201-206. International Iberdesh 2002 Conference, Valencia, Spain, SEP 25-27, 2002. doi:10.1177/ 1082013030335522

Ratti, C. (1991). Diseño de secaderos de productos frutihorticolas. Tesis Doctoral. Universidad Nacional del Sur, Bahía Blanca, Argentina.

Ratti, C. (1994). Shrinkage during drying of foodstuffs. Journal of Food Engineering, 23(1), 91-105. doi:10.1016/0260-8774(94) 90125-2

Roos, Y. (1995). Phase transitions in foods. san diego: academic press.

Schultz, E. L., Mazzuco, M. M., Machado, R. A. F., Bolzan, A., Quadri, M. B., \& Quadri, M. G. N. (2007). Effect of pre-treatments on drying, density and shrinkage of apple slices. Journal of Food Engineering, 78(3), 1103-1110. doi:10.1016/j.jfoodeng.2005.12. 024

Suzuki, K, Kubota, K, Hasegawa, T, \& Hosaka, H. (1976). Shrinkage in dehydration of root vegetables. Journal of Food Science, 41(5), 
Effect of shrinkage on the drying kinetics of foods $\mid 211$

1189-1193. doi:10.1111/j.1365-2621.1976.

tb14414.x

Toma Vanacore, S., Chaves, M., \& J.R., A. (2006). Cinética de secado de zucchini. Comunicaciones Científicas y Tecnológicas 2006: 1-4. Resumen: E-032. Universidad Nacional del Nordeste - Argentina.

Vullioud, M, Marquez, C., \& De Michelis, A. (2004). Desorption isotherms for sweet and sour cherry. Journal of Food Engineering, 63(1), 15-19. doi:10.1016/S0260-8774(03) 00277-2

Vullioud, M., Marquez, C. A., \& De Michelis, A. (2006). Equilibrium sorption isotherms and isosteric heat of rose hip fruits (rosa eglanteria). International Journal of Food Properties, 9(4), 823-833. doi:10.1080/ 109429106007166 